SPECIAL

- COMMUNICATION-

Volume 13 Issue 12021

DOI: 10.21315/eimj2021.13.1.7

ARTICLE INFO

Submitted: 07-07-2020

Accepted: 03-01-2021

Online: 31-03-2021

\section{Tackling Neurophobia among Medical Professionals from Its Inception: Role of Medical Curriculum to Treat This Epidemic Phenomenon}

\author{
Noor Azzizah Omar \\ Department of Anatomy, Faculty of Medicine and Health Sciences, \\ Universiti Sains Islam Malaysia, Negeri Sembilan, MALAYSIA
}

To cite this article: Noor Azzizah Omar. Tackling neurophobia among medical professionals from its inception: role of medical curriculum to treat this epidemic phenomenon. Education in Medicine Journal. 2021;13(1):73-85. https://doi.org/10.21315/eimj2021.13.1.7

To link to this article: https://doi.org/10.21315/eimj2021.13.1.7

\begin{abstract}
Neurophobia is a term used to describe the fear of any topic related to neurology due to failure to integrate basic science knowledge to clinical situation. It has been found that majority of first liner medical staff felt less confident in dealing with patients with neurological illness. This is rather alarming since as the improvement of medical facilities in the recent decade, the age span of the population increases hence, so does their related neurological diseases. Probing into this phobia among the medical professionals has led to one common problem-their undergraduate experience. It has documented that high percentage of disinterest to neurological subject due to its teaching methods and the complexity of the topics. The aim of the study was to discuss on various teaching strategies to overcome this phobia. It has been found that vertical and horizontal integration has been beneficial in augmenting students understanding and retention of knowledge. Thus, it has been implemented and suggested as the suitable curriculum format in medical undergraduate programme. Apart from that, in coherence of IR 4.0 era, there are many innovative teaching techniques that have been studied over the years to facilitate teaching and promote students' motivation towards neurological topics. However, some traditional sessions such as dissections classes still are very much relevant in pre-clinical teaching sessions. Neurophobia has been an "epidemic disease" for decades. The role of tailoring teaching methods to meet with the current students' need has shown promising result to tackle this issue.
\end{abstract}

Keywords: Neurophobia, Medical education, Neuroscience, Teaching methods, Vertical integration, Horizontal integration 


\section{INTRODUCTION}

Neurological diseases have claimed its significance over the past decades and will continue to increase in the next decades to come as the growing of older age group population increases (1). A study conducted in the United Kingdom has found that $6 \%$ of the population had neurological disease some time in their life especially for old age group (2). In 2005, WHO has estimated that neurological diseases contribute to up to $10.9 \%$ of global burden of disease and $12 \%$ of cause of deaths globally. Although it has a relatively low mortality rate, it accounts for $28 \%$ of all years of life living with disability (3-4). A study conducted in the United States has disscussed the implication of growing number of neurological cases as the population ages. In this article, it has been postulated that by 2020 , the demand for neurologist will outstrip the supply by $20 \%$ (5). So, where do all the other cases could turn to?

There was a study debated on who is responsible in taking care of patients with chronic neurological illness. In this discussion, it has been said that neurologist is not the sole specialty that is responsible in taking care of these patients as it requires a multidisciplinary approach (3). Thus, it is important for all health care providers to be well versed in attending patients with neurological conditions (6). However, sadly in a study conducted among medical practitioner, it has been found that they are least confident in dealing with patients with neurological conditions (6). This has been linked to poor performance in diagnosing neurological related diseases (7-8). This condition is alarming as it will exponentially impact the performance of said medical doctors and professionals. It has been reported that lack of confidence in dealing with patients with neurological conditions has led to unnecessary referrals to the neurologist (9). Apart from that, increasing concerns on neurophobia phenomenon dealing with psychiatric illnesses was described in a study that emphasised on neurology knowledge to identify and manage psychiatric patients (10).

The term "neurophobia" was first coined in 1994 by a neurologist who described it as fear of any topic related to neurology due to failure to integrate knowledge of basic science to clinical situation (11). Javaid et al. (12) did a study on understanding of undergraduate students in various medical disciplines on their perspective on different anatomy subjects. They have found that neuroanatomy has been perceived as a difficult subject amongst all anatomy subject. This was also being supported by a study among medical practitioner conducted in 2002 by Schon et al. (7). They had found that their participants who perceived neuroanatomy as the most difficult subject among other subjects. Over the years, this issue has never been resolved. A similar study conducted few years later has shown similar results with Schon et al. (7) where students perceived neurology as the most difficult subject in medical field and has the least knowledge in this field (8).

There are many studies conducted to find the reason of neurophobia. It has been well documented in various studies about the understanding of basic neurology is the key to unlock neurophobia $(7,12)$. In a study conducted among medical students at a few universities in Saudi Arabia found that $70.4 \%$ of students lost interest in neurology due to bad teaching experience whilst $82.5 \%$ perceive that neurological clinical examination is complex (13). Neuroanatomy subject in particular is of concern knowledge when it comes to understanding patients with neurological complaints (6). It is alarming to find that they understand neuroanatomy the least among other subjects (14). This alarming data should provoke a shift in paradigm for the academician to tackle this issue. How do we improve the students' understanding on neurological topics and abolish this neurophobia stigma? In an article written by Sandrone et al. (15), where they have teamed up a group of neurologist and medical educator to come 
up with a consensus to prevent the genesis of neurophobia, significant care need to be addressed on how the students are taught in medical school. Thus, this article aims to explore on some aspects that can be addressed in the medical curriculum and the teaching strategies that might affect the students' perceptions on neurology education.

\section{TACKLING THE CURRICULUM CONTENT: DOES INTEGRATION PROVIDE BENEFITS?}

\section{The Traditional Curriculum}

Neuroscience is a big umbrella topic that consist of collaboration of many units in medical faculty. In the pre-clinical setting, neuroscience is taught from anatomy, physiology, biochemistry and branches of pathology perspectives while in clinical years, neuroscience is related in most of the fields, especially in medicine, neurosurgery, paediatrics and psychiatry. The teaching and learning techniques have always been a debate among educationist on which technique is most effective in enhancing students' understanding. In order to look at the factor of neurophobia among undergraduates, it is a good approach to look at the curriculum that they went through. It is important to analyse how the curriculum is built in as a whole rather than looking at a specific topic.

During the initial development of medical teaching, students were trained as apprentices and taught by the elders. Following that, during 10th century, pre-academic teaching started where there were institutions built with initial development of pedagogy. It was not until 16 th to 17 th century that the knowledge was not only taught by experience but also with experiments and observations. Subsequently, with further progress in education and health, it was in the 19th century where modern scientific medicine has been established. This was when the laboratory-based disciplines transformed into basic teaching such as physiology, pathology and bacteriology (16). It was in 1910 following Flexner's report that the medical education underwent a dramatic change that has led to a structured and standardised system. The medical education was reorganised into pre-clinical teaching and was conducted in the first two years in the undergraduate programme comprising lectures and laboratory work and two years of clinical teaching (17).

As a result, the so-called "traditional method" of modern medicine was applied where each of the subjects was taught as a stand-alone unit during the initial era of modern medical curriculum. In the context of neuroscience, it was taught in disciplinebased curriculum where each department teach their topics according to their own arrangements. This may have contributed to potential disintegration of knowledge when they are taught in different timing and setting. Currently, although minority, there are medical school that practices traditional medical curriculum in the effort of preserving beneficial knowledge in each of the disciplines. A survey conducted among medical students showed one of the major cause in causing fear in neurosciences topic is due to the poor understanding of their basic knowledge in pre-clinical years (14). This may be due to disconnected overload knowledge with lack of critical thinking as reported by another survey which has led to negative influence on their factual understanding (18). The traditional curriculum, although has provided enormous amount of beneficial knowledge to the students, may also initiated the fear to the subject due to overloading and lack of linkage in between the disciplines. It is probably timely for the policy maker in the medical school to revisit on how to improvise their current curriculum. 


\section{The Birth of Integration}

Shoemaker defined an integrated curriculum as "education that is organised in such a way that it cuts across subject-matter lines, bringing together various aspects of the curriculum into meaningful association to focus upon broad areas of study" (19). In medical education, the two basic type of integration that are widely discussed is horizontal integration and vertical integration. Horizontal integration involves learning within the same structure where individual subject areas contribute to the learning process in a holistic manner (20). In this case, the pre-clinical department collaborate to develop a module to teach together in a systematic fashion. It has been shown that horizontal integration has improved the students' understanding and knowledge retention compared to traditional discipline-based teaching (21). This could be due to collaboration and standardisation of topics that are learnt coherently, hence students understand a specific structure in terms of its anatomy, physiology and related biochemical properties rather than learning it under three separate entities.

There are medical universities that have reviewed their curriculum and incorporated horizontal integration in the pre-clinical years. There are two studies conducted in the pre-clinical students in India comparing traditional discipline-based teaching and horizontal integration. In this study, students are group in two pools, traditional group and study group. There were taught in traditional discipline and horizontally integrated system, respectively. The study group has shown significance improvement in their assessment compared to the traditional group. This shows that the horizontal integration provides benefits in students' comprehension on knowledge (22-23). This method is worthwhile to be addressed especially in universities that practicing a pure traditional method of teaching. However, despite the parallel change into horizontal integration, will that be enough in causing significant improvement in students' understanding and passion towards neurology related topics? As in this era, there are more medical universities that practices horizontally integrated than traditional curriculum, however, the neurophobia phenomenon is still significantly prevalent worldwide.

Studies have documented that teaching methods were not adequate to cover important information in neurology related topics (7-8). In these studies, they have emphasised the lack of integration of basic science with clinical setting that has promoted the incidence of neurophobia as they failed to relate patients' condition to the basic structure and function (7-8). A retrospective study conducted among medical doctors that have experienced a traditional curriculum found that they felt inadequate and unprepared when they start practicing, as they are not exposed to the real-life experiences and everything where taught in segmented manner (24). This is where vertical integration comes to play. Vertical integration involves incorporating basic pre-clinical knowledge with clinical setting and vice versa (21). Haines et al. (25) have described that a dense integration of anatomy and radiological orientation in neuroanatomy teaching has markedly improved students' understanding and preparedness in their clinical postings compared to conventional compartmentalised teaching method. The students were followed-up during their clinical years and was seen to be more prepared to attend to neurological cases and were given good remarks by their attending lecturers (25).

Another study conducted in India implementing vertical integration to their previously traditional discipline-based curriculum. In this new curriculum, they have incorporated case-based learning, case stimulated interactive lectures, clinical seminars and patients' exposure along with their didactic lectures. The timetable was adjusted to integrate anatomy, biochemistry and physiology horizontally as well. At 
the end of study, majority of students felt that the recent system has improved their understanding and motivation towards neuroscience topics (26). This theory has been conducted by medical students where they were introduced with casebased learning that allows integration of basic physiology and anatomy with clinical medicine. In this study, students feel this method has improved their understanding in neurological related topics and requested for more similar sessions (27). Coherent with this finding, a medical school in Sweden conducted a study of reviewing their vertical integration and found that this has provided benefit in terms of gaining deeper level of learning and understanding among students (28).

The vertical integration works both ways to help the pre-clinical students to understand the important on learning structures and functions, and for the clinical students to understand the basic mechanism of disease and its pathogenesis. The clinical undergraduate may benefit significantly with a flash course on their basic sciences prior to each posting to enhance their understanding. A study conducted among final year medical students on integrating neuroanatomy course prior to their medical posting. This study found that the course helped the students to understand their clinical cases better. This had been portrayed with better post course test. Apart from that, their summative exam scores were significantly higher compared to the control group. The students have reported that neurological diseases are not as frightening after understanding the basic sciences prior to their medical posting (29).

The vertical integration is not only limited in the medical school but rather throughout their life-long learning. There was a study conducted among residents of primary care in Portugal. In this study, they have offered intensive clinical neuroanatomy course among the residents. They have found that there is a $120 \%$ improvement in the test to evaluate their understanding on the structures and neurological diseases post-intensive course. Apart from that, the residents also reported that they attended to the integrated intensive course and had improved their understanding on neuroscience significantly (30). This "reverse" method is undoubtedly beneficial for the clinical students and practicing medical professionals in view of they might lose touch in the basic structures or mechanisms as their focus now are more towards the disease and the prognosis. The refreshment course unsurprisingly may aid in their decision and management of patients after considering and remembering on how human body works in the normal condition.

Apart from looking at the students' point of view, it is also beneficial to look at the educators view on the curriculum content. Perception on horizontal and vertical integration was collected in a study conducted among the faculty members of health sciences following incorporation of problem-based learning session in their curriculum. In this study, the faculty members supported the horizontal and vertical integration curriculum as it had shown to improve students' understanding and hence the retention of knowledge (31). A study conducted in India has found that a majority of their members agreed on vertically integrating their subject content for better students' understanding on the topic during both pre-clinical and clinical years (32).

It is important to note that traditional curriculum does hold a great merit in teaching the medical students especially in terms of depth of knowledge. However, as the era progresses with the Generation $\mathrm{Z}$ (Gen $\mathrm{Z}$ ) nowadays who are fast thinkers and often has shorter term of attention (33), hence this method might not be relevant anymore. Certainly, it is a significant change from the traditional method where extra efforts are needed from the policy maker to reorganise the whole subjects and arrange them to be appeared synchronous and coherent. This might pose a challenge in small universities that may have issues with 
academic staff numbers and experiences. However, it is important to note that a great teamwork work both ways, hence the preclinical and the clinical team may share the burden equally to improve their curriculum structure.

\section{TACKLING THE CONTENT DELIVERY: IS DIDACTIC LECTURES AND TRADITIONAL DISSECTION STILL RELEVANT?}

\section{Improvisation of Original Technique}

Despite promising result in integrated curriculum, Youssef (8) has reported that despite the change in medical curriculum with more vertical integration sessions between pre-clinical and clinical knowledge, it has failed to improve students' perception towards neurology. Thus, changes should not be within the curriculum alone. Apart from improving their understanding, their interest in this relatively challenging topic should be reviewed as well. Dense studies have been conducted looking into content delivery and how it affects the understanding in neurological topics including neuroanatomy. The academicians need to prepare their strategies for the current Gen $\mathrm{Z}$ that are in the verge of entering college period. It has been documented that as the generation progresses, they tend to be more technologydriven and fast thinkers (34-35). Thus, the traditional method of giving didactic lectures are gaining less popular amongst the current and future students.

However, despite gaining less popularity and frequently scrutinised on its significance, lectures have shown to be still appreciated by medical undergraduates. According Kolb's cycle of experiential learning in 1984, learning is a cycle that starts with concrete experience followed by reflective observation then abstract conceptualisation and active experimentation (36). This experiential learning cycle has emphasised the importance of "together time" during the concrete experience phase as to gain a concrete knowledge from a trained individual. It has been discussed that together time enable learners to validate, consolidate and reframe concepts that is refined by the lecturers (37). In par with the current generation, improvisation of the current didactic lecture has shown to be beneficial. Students have responded in a study that the lectures provide beneficial input to them if it was engaging enough and augmented with visual stimuli such as video (38). This video-assisted learning is one of the alternatives among various sort that has been carried out globally to tackle the students' interest during the teaching and learning session. This method uses videoincorporated lectures or session to improve the students' understanding, which has gained positive response from the students as it was documented improvement in students' satisfaction and understanding on the subject (39-40). These studies support the idea of the current students who need more engaging sessions with breaks in between with videos for them to focus more on the session.

This technique is also applicable in flipclassroom where the concept of together time during introduction of new concept and "homework time" is flipped. The students are introduced to the new concepts prior to classroom time through various sorts of method such as instructional video, readings and video assisted lectures. The students spend time together after their individual learning time (41). Schaefer et al. have suggested that video-based neuroanatomy learning with in-person tutorials is one of the suitable technique in aiding focus and understanding through flipclassroom session (37). However, not all topics are suitable with video sessions and some videos may take longer than the other. Thus, the academicians need to weigh the benefits of having video incorporation in their lectures. 


\section{Bringing the Student as the Primary Role in Teaching: The Student-Centred Pedagogy}

In 1964, Edgar Dale has formulated cone of experience where he concluded that students retain a concrete best knowledge when they are actively involved in the teaching and learning sessions (42). Despite being a model created decades ago, it is still relevant in this era. It is documented that Gen $\mathrm{Z}$ prefers sessions that they can actively participate in (43). This has led to various efforts by the medical faculty to initiate a student-centred approach where student played the main role during teaching and learning sessions. The power of peer in their teaching and learning sessions has been utilised medical schools such as small group discussion (SGD) sessions. In this session, students are grouped in a small group to discuss on certain topics. Students are required to present and defend their finding among their peers during the session.

The concept of SGD was further developed into many varieties such as team-based learning (TBL), problem-based learning (PBL) and case-based learning (CBL). TBL session has gain its popularity in the recent years. In this session, students are required to self-study prior to the session. During the session, there will be an assessment on individual's readiness assurance test (iRAT) and subsequently reassessed again in the team's readiness assurance test (tRAT). During tRAT, students are required to discuss the questions provided with the team members to achieve a consensus. TBL is then ended with discussion facilitated by the instructor (44). This allow immediate students' feedback while promoting controlled SGD. Studies have found that teaching neuroscience through TBL sessions help in gaining, understanding and synthesising knowledge while boosting their motivation to learn (44-46). Apart from that, TBL resulted in better students' performance in their examination (44), compared to basic active learning sessions such as SGD (46). Yang et al. (47), however showed in their study that combination of lecture and TBL is more superior than TBL alone.

In PBL, students are grouped in small groups which consist of initial clinical presentation of a patient. They are required to solve the problem faced by the patient and relate it with their basic medical knowledge through discussions among their peers (48-49). Barrows and Mitchell (48) who initiated PBL method in 1975 has started it with "problem boxes" in neuroscience curriculum. It was documented that PBL sessions has improved their knowledge and confidence in handling neurological questions by the pre-clinical medical students (50) and significantly improved their examination assessment (51). However, it is important to note that PBL sessions require quite a number of trained professionals who are subject experts in the subject discussed. Trappler (52) conducted a PBL in a neuroscience curriculum. In the study, students preferred a larger group of PBL session as they can meet expert facilitators rather than small group with non-expert facilitators. They also expressed their frustration of having to cut out lectured as they appreciated their didactic lectures to improve their understanding (52). Hence, it is important to weigh out on how much to integrate the sessions, so the students can experience various mode of learning adequately.

CBL on the other hand has a similar concept with PBL but consist of more thorough clinical presentation that leads to linkage of theory to practice through application of knowledge using inquirylearning method with discrete learning objectives (53-54). The students are given a complete case scenario that need them to solve the questions, relate it with basic knowledge and understand the principle of management in a guided inquiry approach. A study conducted in multiple universities on perception of students and faculty members on PBL and CBL sessions showed that students preferred CBL session 
compared to PBL session in terms of better use of time with fewer unfocused tangents. However, the students perceived PBL has motivated them on independent and selfdirected learning (55).

Another session that uses the concept of peer teaching is known as near-peer teaching sessions where the senior students act as a mentor in tutoring their juniors in a small group session. This has been documented to provide benefit in students' understanding and teacher's reflection on their own understanding on neuroanatomy (56-57). These sessions have benefited both parties as the "teachers" while reflecting on their own knowledge, they are also being asked by the students which stimulates both of the parties thinking process. However, it is important to be reminded that the senior students may have other commitments and teaching scheduling in their current year which makes these sessions a challenge to be arranged in the timetable. These recommended teaching methods emphasises that innovating the traditional teaching with or without computer or software assistance is possible. This will be a helpful input in certain universities that faces budget constraints. Each of the sessions has shown to have its benefits and drawbacks. It is vital for the policy maker of the faculty to weigh what are suitable for their cohort and always reanalyse on the effectiveness of their current content delivery methods.

\section{Getting Help from Gen Z's Best Companion: Technology-Assisted Teaching}

In order to teach Gen $Z$, we need to become Gen $\mathrm{Z}$ in terms of learning style and teaching. Following this, visual augmentation strategy during teaching has been adapted incorporating the usage of computer. Computer-assisted learning (CAL) using virtual stimulation has also shown positive impact not only on understanding but has improved their interest during teaching and learning sessions (58-59). Parallel to this effort, Lim and Seet have conducted a teaching via online gaming technology where the students need to attend a virtual patient and each decision made during the game affects the outcome of the patient. The students responded extremely well from $27 \%$ expressed confidence in interpretation of neurological science before the simulated game to $91 \%$ after the simulation (39). Another study has implemented neurogaming in their practical session to teach the students on electroencephalogram principle. The practical session using electroencephalogram neurogaming is aim to augment the students' understanding by following conventional method teachings. The students responded well during this session and unanimously agreed that the session has helped them to understand the topic more clearly (60).

Latimer et al. (61) have conducted a study on undergraduate students using open source software. This study collaborated with engineering, mathematics, biology and psychology discipline to augment the students' understanding on practicality and physics of neurosciences basic knowledge. The course has shown positive impact on students understanding on the basic core knowledge on neuronal functions and conductivity (61). In another study, computer-assisted teaching and learning is conducted in a cheaper and more friendly way via social media. This study has used social media as a platform to share interesting facts, quizzes and discussion for limitless undergraduates' access. The usage of this method had significantly improved students' performance in exam portraying their improvement in understanding the topics (62). This is one of the examples that can be used for faculties that has difficulties in getting education funds for materials of teaching while making learning fun and approachable by the students.

Although computer-assisted teaching and learning has gained more popularity, it is worth to be reminded that some rather traditional methods are still relevant and very much useful in teaching neurology especially in neuroanatomy. A study 
conducted in 2016 has found that practical session such as brain dissection has not only improved students' performance post-practical session but also significantly improved their knowledge retention (63). However, it is a global struggle to get a good specimens' storage for every student, thus post a challenge in the majority of medical school worldwide. In view of this, they have to rely on prosected material with limited time per specimens as they have to share during the practical session. In attempt to augment learning process, online three-dimensional model during practical sessions has shown significant improvement in students' understanding on difficult neuroanatomy structures (64-65).

While there are many methods that have been suggested in literatures, each medical school need to tailor their programme based on their facilities, academic staff and the students' cohort. The most important aspect in managing curriculum is always to have a feedback or audit session to reflect on the effectiveness of the current system. As discussed previously, each batch of generations are different in terms of their adaptation skills to new information. Thus, as an academician, it is important to recognise this hidden factor in organising and planning the teaching sessions. It is utmost vital to carefully plan the neurologybased topics from the very beginning, undergraduate level itself as their first impression may give a cascade effect on how they perceive neurology in the future.

\section{CONCLUSION}

Neurophobia among medical professionals is alarmingly common. Academicians need to be more proactive and creative in dealing with this from their undergraduate years. A combination of integrated curriculum with various teaching techniques has proven the improvement of students understanding, therefore, potentially may tackle the phobia when they start to practice.

\section{ACKNOWLEDGEMENTS}

Author would like to express deepest gratitude to the Faculty of Medicine and Health Sciences, Universiti Sains Islam Malaysia for supporting the review article writing. There is no research funding involved in this study.

\section{REFERENCES}

1. Menken M. Demystifying neurology. BMJ. 2002;324(7352):1469-70. https://doi. org/10.1136/bmj.324.7352.1469

2. MacDonald BK, Cockerell OC, Sander JWAS, Shorvon SD. The incidence and lifetime prevalence of neurological disorders in a prospective community-based study in UK. Brain. 2002;123:665-76. https://doi. org/10.1093/brain/123.4.665

3. Menken M, Munsat, TL, Toole JF. The global burden of disease study. Archives of Neurology. 2003;57(3):418. https://doi. org/10.1001/archneur.57.3.418

4. Neurological disorders: public health challenges. Arch Neurol. 2008;65(1):154. https://doi.org/10.1001/archneurol.2007.19

5. Bradley WG. Neurology in the next two decades: report of the workforce task force of the American Academy of Neurology. Neurology. 2000;54(4):787-9. https://doi.org/10.1212/wnl.54.4.787

6. Zinchuk AV, Flanagan EP, Tubridy NJ, Miller WA, Mccullough LD. Attitudes of US medical trainees towards neurology education: "Neurophobia" - a global issue. BMC Med Educ. 2010; 10:49. https:// doi.org/10.1186/1472-6920-10-49

7. Schon F, Hart P, Fernandez C. Is clinical neurology really so difficult? J Neurol Neurosurg Psychiatry. 2002;72(5):557-9. https://doi.org/10.1136/jnnp.72.5.557 
8. Youssef FF. Neurophobia and its implications: evidence from a Caribbean medical school. BMC Med Educ. 2009; 9(1):1-7. https://doi.org/10.1186/14726920-9-39

9. Ridsdale L, Massey R, Clark L. Preventing neurophobia in medical students, and so future doctors. Pract Neurol. 2007;7(2):116-23.

10. Bullmore E, Fletcher P, Jones PB. Why psychiatry can't afford to be neurophobic? Br J Psychiatry. 2009;194(4):293-5. https:// doi.org/10.1192/bjp.bp.108.058479

11. Jozefowicz RF. Neurophobia: the fear of neurology among medical students. Arch Neurol. 1994;51(4):328-9. https://doi.org/10.1001/archneur.1994 .00540160018003

12. Javaid MA, Chakraborty S, Cryan JF, Schellekens H, Toulouse A. Understanding neurophobia: reasons behind impaired understanding and learning of neuroanatomy in cross-disciplinary healthcare students. Anat Sci Educ. 2017;11(1):81-93. https://doi.org/10.1002/ ase. 1711

13. Abulaban AA, Obeid TH, Algahtani HA, Kojan SM, Al-Khathaami AM, Abulaban AA, et al. Neurophobia among medical students. Neurosciences (Riyadh). 2015;20(1):37-40.

14. Mccarron MO, Stevenson M, Loftus AM, Mckeown P. Neurophobia among general practice trainees: the evidence, perceived causes and solutions. Clin Neurol Neurosurg. 2014;122:124-8. https://doi. org/10.1016/j.clineuro.2014.03.021

15. Sandrone S, Berthaud JV, Chuquilin M, Cios J, Ghosh P, Gottlieb-Smith RJ. Neurologic and neuroscience education: mitigating neurophobia to mentor health care providers. Neurology. 2019;92(4):174-9. https://doi.org/10.1212/ WNL.0000000000006716.
16. Gourevitch D. The history of medical teaching. Lancet. 1999;354(Suppl):SIV33. h t t p s://doi.org/10.1016/s 0140 6736(99)90376-8.

17. Flexner A. Medical education in the United States and Canada: a report to the carnegie foundation for the advancement of teaching, bulletin number four, 1910. Bull World Health Organ. 2002;80(7):594-602.

18. Schei E, Johnsrud RE, Mildestvedt T, Pedersen R, Hjorleifsson S. Trusting bewildered. How first-year medical students make sense of their learning experience in a traditional, pre-clinical curriculum. Med Educ Online. 2018;23(1):1500344. https:// doi.org/10.1080/10872981.2018.1500344

19. Shoemaker BJE. Integrative education: a curriculum for the twenty-first century. OSSC Bulletin. 1989;33(2):1-46.

20. Gullo C, Dzwonek B, Miller B. A diseasebased approach to the vertical and horizontal integration of a medical curriculum. Medical Science Educator. 2015;26(1):93-103. https://doi.org/10.1007/s40670-015-0208-5

21. Atwa HS, Gouda EM. Curriculum integration in medical education: a theoretical review. Intellectual Property Rights: Open Access. 2014;2(2):1-7. https:// doi.org/10.4172/2375-4516.1000113

22. Gaddam V, Gowda V, Vaidyanathan K. Comparison of the effectiveness of horizontal integration with traditional teaching approach in first-year MBBS students. International Journal of Medical Science and Public Health. 2016;5(7):1360. https://doi. org/10.5455/ijmsph.2016.07102015202

23. Basu M, Das P, Chowdhury G. Introducing intergrated teaching and comparison with traditional teaching in undergraduate medical curriculum: a pilot study. Medical Journal of Dr. DY Patil Vidyapeeth. 2015;8(4):431-8. https://doi. org/10.4103/0975-2870.160778 
24. Watmough S, O'Sullivan $\mathrm{H}$, Taylor D. Graduates from a traditional medical curriculum evaluate the effectiveness of their medical curriculum through interviews. BMC Med Educ. 2009;9:64. https://doi. org/10.1186/1472-6920-9-64

25. Haines DE, Hutchins JB, Lynch JC. Medical neurobiology: do we teach neurobiology in a format that is relevant to the clinical setting? Anat Rec. 2002;269(2):99-106. https://doi. org/10.1002/ar.10073

26. Ghosh S, Pandya HV. Implementation of integrated learning program in neurosciences during first year of traditional medical course: perception of students and faculty. BMC Med Educ. 2008;8(1):44. https://doi.org/10.1186/1472-6920-8-44

27. Hudson J. Linking neuroscience theory to practice to help overcome student fear of neurology. Med Teach. 2006;28(7):651-3. https://doi.org/10.1080/01421590600726409

28. Dahle LO, Brynhildsen J, Fallsberg MB, Rundquist I, Hammar M. Pros and cons of vertical integration between clinical medicine and basic science within a problembased undergraduate medical curriculum: examples and experiences from Linköping, Sweden. Med Teach. 2002;24(3):280-5. https://doi.org/10.1080/01421590220134097

29. Arantes M, Barbosa JM, Ferreira MA. Neuroanatomy education: the impact on perceptions, attitudes, and knowledge of an intensive course on general practice residents. Anat Sci Educ. 2017;10(5):46574. https://doi.org/10.1002/ase.1686

30. Rajan S, Jacob T, Sathyendra S. Vertical integration of basic science in final year of medical education. Int J Appl Basic Med Res. 2016;6(3):182-5. https://doi. org/10.4103/2229-516X.186958
31. Brynhildsen J, Dahle LO, Fallsberg MB, Rundquist I, Hammar M. Attitudes among students and teachers on vertical integration between clinical medicine and basic science within a problem-based undergraduate medical curriculum. Med Teach. 2002;24(3):286-8. https://doi. org/10.1080/01421590220134105

32. Panda M, Biswas M. Perception of faculty on vertical integration - as a teaching learning method in undergraduate medical education. Journal of Evolution of Medical and Dental Sciences. 2019;8(14):1120-3. https://doi.org/10.14260/jemds/2019/248

33. Shatto B, Erwin K. Moving on from millennials: preparing for Generation Z. Journal of Continuing Education in Nursing. 2016;47(6):253-4. https://doi. org/10.3928/00220124-20160518-05

34. Rockwood K, Hogan H, Patterson C. Incidence of and risk factors for nodding off at scientific sessions. American Journal of Ophthalmology. 2005;139(5):958-9. https:// doi.org/10.1016/j.ajo.2005.03.015

35. Pew Research Centre [Internet]. Washington, DC: Pew Research Centre; 2014 Mar 7 [cited 2020 Sep 1]. Millenials in adulthood: detached from institution, networked with friends. Available from: https://www.pewsocialtrends. org/2014/03/07/millennials-in-adulthood/

36. Kolb DA. Experiential learning: experience as the source of learning and development. Englewood Cliffs, NJ: Prentice-Hall; 1984 cited in Schaefer S, Dominguez M, Moeller J. The future of the lecture in neurology education. Semin Neurol. 2018;38(4):41827. https://doi.org/10.1055/s-0038-1667042

37. Schaefer S, Dominguez M, Moeller J. The future of the lecture in neurology education. Semin Neurol. 2018;38(4):418-27. https:// doi.org/10.1055/s-0038-1667042 
38. O'Keeffe GW, Sullivan AM, McCarthy MM. An attitudinal survey of undergraduate neuroscience students regarding their views on the relevance of lectures to their education. J Undergrad Neurosci Educ. 2017;16(1):A28-33.

39. Lim EC, Seet RC. Demystifying neurology: preventing neurophobia among medical students. Nat Clin Pract Neurol. 2008;4(8):461-2. https://doi.org/10.1038/ ncpneuro0849

40. Lim EC-H, Ong BKC, Wilder-Smit EPV, Seet RCS. Sustaining interest during lectures with the use of multimedia. Med Educ Online. 2006(May):1-4.

41. Khan S. The one world school house: education reimagined. New York, NY: Twelve; 2012 cited in Schaefer S, Dominguez M, Moeller J. The future of the lecture in neurology education. Semin Neurol. 2018;38(4):418-27. https://doi. org/10.1055/s-0038-1667042

42. Masters K. Edgar Dale's pyramid of learning in medical education: a literature review. Med Teach. 2013;35(11):e1584-93. https:// doi.org/10.3109/0142159X.2013.800636

43. Seemiller C, Grace M. Generation Z: educating and engaging the next generation of students. About campus. 2017;22(3):216. https://doi.org/10.1002/abc.21293

44. Brich J. Feasibility, acceptance and impact of team-based learning in neurology: a pilot study. GMS Z Med Ausbild. 2013;30(2):Doc20. https://doi.org/10.3205/ zma000863

45. Abushouk AI, Duc NM. Curing neurophobia in medical schools: evidencebased strategies. Med Educ Online. 2016;21(1):32476. https://doi.org/10.3402/ meo.v21.32476

46. Ng M, Newpher TM. Comparing active learning to team-based learning in undergraduate neuroscience. J Undergrad Neurosci Educ. 2020;18(2):A102-A11.
47. Yang LH, Jianh LY, Xu B, Liu SQ, Liang YR, Ye JH, Tao EX. Evaluating teambased, lecture-based and hybrid learning methods for neurology clerkship in China: a method-comparison study. BMC Med Educ. 2014;14(98):1-7. https://doi. org/10.1186/1472-6920-14-98

48. Barrows HS, Mitchell DLM. An innovative course in undergraduate neuroscience: experiment in problembased learning with 'problem boxes'. Br J Med Educ. 1975;9(4):223-30. https://doi. org/10.1111/j.1365-2923.1975.tb01930.x.

49. Barrows HS, Tamblyn RM, editors. Problem-based learning: an approach to medical education. New York: Springer; 1980.

50. Shiels L, Majmundar P, Zywot A, Sobotka J, Lau CSM, Jalonen TO. Medical student attitudes and educational interventions to prevent neurophobia: a longitudinal study. BMC Med Educ. 2017;17(225):1-7. https:// doi.org/10.1186/s12909-017-1055-4

51. Heckmann JG, Bleh C, Dütsch M, Lang CJG, Neundörfer B. Does improved problem-based teaching influence students' knowledge at the end of their neurology elective? An observational study of 40 students. J Neurol. 2003;250:1464-8. https://doi.org/10.1007/s00415-003-0255-5

52. Trappler B. Integrated problem-based learning in the neuroscience curriculum - the SUNY downstate experience. BMC Med Educ. 2006;6:47. https://doi. org/10.1186/1472-6920-6-47

53. Thistlethwaite JE, Davies D, Ekeocha S, Kidd JM, MacDougall C, Matthews P, Purkis P, Clay D. The effectiveness of case-based learning in health professional education. A BEME systematic review: BEME Guide No. 23. Med Teach. 2012;34(6):421-44. https://doi.org/10.3109/ 0142159X.2012.680939 
54. McLean SF. Case-based learning and its application in medical and health-care fields: a review of worldwide literature. J Med Educ Curric Dev. 2016;3:JMECD.S20377. https://doi.org/10.4137/JMECD.S20377.

55. Srinivanisan $M$, Wilkes $M$, Stevenson F, Nguyen T, Slavin S. Comparing problembased learning with case-based learning: effects of a major curricular shift at two instituition. Acad Med. 2007;82(1):7482. https://doi.org/10.1097/01. ACM.0000249963.93776.aa

56. Harrison CH, Elmansouri A, Parton W, Myers MA, Hall S, Stephens JR, et al. The efficacy of frontline near-peer teaching in a modern medical curriculum. Anat Sci Educ. 2018;12(3):236-44. https://doi.org/10.1002/ ase. 1827

57. Hall S, Lewis M, Border S, Powell M. Nearpeer teaching in clinical neuroanatomy. Clin Teach. 2013;10(4):230-5. https://doi. org/10.1111/tct.12001

58. Ziv A, Wolpe PR, Small SD, Glick S. Simulation-based medical education. Acad Med. 2003;78(8):783-8. https://doi. org/10.1097/00001888-200308000-00006

59. Stepan K, Zeiger J, Hanchuk S, Hanchuk S, Del Signore A, Shrivastava R, Govindaraj S, et al. Immersive virtual reality as a teaching tool for neuroanatomy. Int Forum Allergy Rhinol. 2017;7(10):1006-13. https://doi. org/10.1002/alr.21986
60. De Wit B, Badcock NA, Grootswagers T, Hardwick K, Teichmann L, Wehrman $\mathrm{J}$, et al. Neurogaming technology meets neuroscience education: a costeffective, scalable, and highly portable undergraduate teaching laboratory for neuroscience. J Undergrad Neurosci Educ. 2017;15(2):A104-9.

61. Latimer B, Bergin D, Guntu V, Schulz D, Nair S. Open source software tools for teaching neuroscience. J Undergrad Neurosci Educ. 2018;16(3):A197-202.

62. Anwar K, Sajid MR, Cahusac P, Shaikh AA, Elgammal A, Alshedoukhy A. Can Facebook pages be a mode of blended learning to supplement in-class teaching in Saudi Arabia? Adv Physiol Educ. 2017;41(3):4727. https://doi.org/10.1152/advan.00065.2017

63. Rae G, Cork RJ, Karpinski AC, Swartz WJ. The integration of brain dissection within the medical neuroscience laboratory enhances learning. Anat Sci Educ. 2016;9(6):565-74. https://doi.org/10.1002/ ase. 1611

64. Estevez ME, Lindgren KA, Bergethon PR. A novel three-dimensional tool for teaching human neuroanatomy. Anat Sci Educ. 2010;3(6):309-17. https://doi.org/10.1002/ ase. 186

65. Allen LK, Eagleson R, Ribaupierre SD. Evaluation of an online three-dimensional interactive resource for undergraduate neuroanatomy education. Anat Sci Educ. 2016;9(5):431-9. https://doi.org/10.1002/ ase. 1604 